\title{
Neslihan şenocak, The Poor and the Perfect, The Rise of Learning in the Franciscan Order, 1209-1310
}

\section{G. Matteo Roccati}

\section{(2) OpenEdition}

\section{Journals}

\section{Édition électronique}

URL : http://journals.openedition.org/studifrancesi/4300

DOI : 10.4000/studifrancesi.4300

ISSN : 2427-5856

\section{Éditeur}

Rosenberg \& Sellier

\section{Édition imprimée}

Date de publication : 1 septembre 2016

Pagination : 302-303

ISSN : 0039-2944

\section{Référence électronique}

G. Matteo Roccati, « Neslihan Senocak, The Poor and the Perfect, The Rise of Learning in the Franciscan Order, 1209-1310», Studi Francesi [En ligne], 179 (LX | II) | 2016, mis en ligne le 01 septembre 2016, consulté le 18 septembre 2020. URL : http://journals.openedition.org/studifrancesi/4300 ; DOI : https://doi.org/10.4000/studifrancesi.4300

Ce document a été généré automatiquement le 18 septembre 2020.

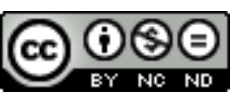

Studi Francesi è distribuita con Licenza Creative Commons Attribuzione - Non commerciale - Non opere derivate 4.0 Internazionale. 


\title{
Neslihan şenocak, The Poor and the Perfect, The Rise of Learning in the Franciscan Order, 1209-1310
}

\author{
G. Matteo Roccati
}

\section{RÉFÉRENCE}

NESLIHAN şENOCAK, The Poor and the Perfect, The Rise of Learning in the Franciscan Order, 1209-1310, Ithaca and London, Cornell University Press, 2012, XVI-276 pp.

1 L'ouvrage se veut «essentially a story of how and why learning became part of the Franciscan way of life, and the consequences of this integration» (p. 2), une histoire perçue comme révélatrice d'un phénomène bien plus large: selon les mots de l'A., «the story of the rise of learning in the Franciscan Order is part of the story of the rise of learning in thirteenth-century France» (p. 24). Dans la tradition historiographique, en projetant dans le passé la fracture entre spirituels et conventuels, l'attitude à l'égard du savoir et de l'enseignement est présentée comme une des questions au cœur de la controverse. L'étude reprend la question à nouveaux frais, en mettant à profit les nouvelles sources publiées depuis 1990, qui rendent possible «a rough reconstruction of the educational organization of the medieval Franciscan Order, as well as a delineation of its evolution» (p. 20), sans se référer à la réalité dominicaine, souvent sollicitée car mieux documentée; bien au contraire l'A. pointe les différences institutionnelles et dans l'inspiration fondamentale des deux ordres: l'imitation de la pauvreté du Christ chez les uns, le travail intellectuel au service de la lutte contre l'hérésie chez les autres.

2 L'exposé est organisé en cinq chapitres. Le premier, «The Formative Years, 1219-1244», retrace les années fondatrices, du refus de toute propriété, y compris les livres, à l'émergence de la figure du lector à la fin des années 1220 (François meurt en 1226), avec une attention spéciale à la politique d'installation de l'ordre dans les villes universitaires (les frères sont à Paris dès 1219, à Oxford et à Cambridge en 1224-1225) et 
à l'importance que prennent les universitaires dans la hiérarchie. Le deuxième chapitre, «Studying as Evangelical Perfection», est consacré à l'évolution de l'identité franciscaine, révélée par le souci d'accroitre le prestige de l'ordre qui apparait dans le recrutement, par les résistances qu'elle suscite, par les modèles de sainteté proposés Antoine de Padoue à côté de François -, par le lien qui s'établit entre pauvreté et étude (celui qui met en pratique l'idéal évangélique est le plus apte à l'enseigner). Le chapitre suivant, «Beyond Preaching and Confession» (III), essaye de cerner les motivations de cette évolution. Les exigences de la prédication et de la pastorale, des activités qui justifient l'étude dès le milieu du xIII ${ }^{e}$ siècle, ne semblent pas déterminantes, l'A. met plutôt en avant la recherche de respectabilité, essentielle pour la survie de l'ordre, et l'attrait exercé par la nouvelle théologie scolastique et son haut lieu, l'université de Paris. Le quatrième chapitre, "Paradise Lost», passe en revue les témoignages (dénonciations et mesures visant les abus) des dérives liées à l'étude pratiquée comme instrument d'avancement et de pouvoir: privilèges abusifs de lecteurs ne remplissant pas leur tâche, possession privée de livres, enseignement de la philosophie. L'A. examine les mécanismes institutionnels qui ont pu les favoriser, mais elle souligne le fait que l'étude en tant que telle n'est jamais remise en question. Enfin le dernier chapitre, «The Educational System around 1310» (V), détaille le système d'enseignement à l'intérieur de l'ordre: l'implantation, les types et la hiérarchie des écoles et des studia, la sélection et le parcours des étudiants, la nature des études, le service fourni au clergé séculier. Après la conclusion, une bibliographie selective (pp. 253-269), un glossaire (pp. 271-272) et l'index (noms et notions, pp. 273-276) complètent ce travail riche en clés de réflexion. 